\title{
Three Postpartum Antiretroviral Regimens to Prevent Intrapartum HIV Infection
}

\author{
Karin Nielsen-Saines, M.D., D. Heather Watts, M.D., Valdilea G. Veloso, M.D., \\ Yvonne J. Bryson, M.D., Esau C. Joao, M.D., Jose Henrique Pilotto, M.D., \\ Glenda Gray, M.D., Gerhard Theron, M.D., Breno Santos, M.D., \\ Rosana Fonseca, M.D., Regis Kreitchmann, M.D., Jorge Pinto, M.D., \\ Marisa M. Mussi-Pinhata, M.D., Mariana Ceriotto, M.D., Daisy Machado, M.D., \\ James Bethel, Ph.D., Marisa G. Morgado, Ph.D., Ruth Dickover, Ph.D., \\ Margaret Camarca, M.P.H., Mark Mirochnick, M.D., George Siberry, M.D., \\ Beatriz Grinsztejn, M.D., Ronaldo I. Moreira, M.Sc., Francisco I. Bastos, Ph.D., \\ Jiahong Xu, M.P.H., Jack Moye, M.D., and Lynne M. Mofenson, M.D., \\ for the NICHD HPTN 040/PACTG 1043 Protocol Team*
}

The authors' affiliations are listed in the Appendix. Address reprint requests to Dr. Nielsen-Saines at the Division of Infectious Diseases, David Geffen School of Medicine, University of California, Los Angeles, MDCC 22-442 10833 LeConte Ave., Los Angeles, CA 90095, or at knielsen@mednet.ucla.edu.

*Members of the National Institute of Child Health and Human Development (NICHD) HIV-1 Prevention Trials Network (HPTN) 040/Pediatric AIDS Clinical Trials Group (PACTG) 1043 protocol team are listed in the Supplementary Appendix, available at NEJM.org.

N Engl J Med 2012;366:2368-79.

Copyright (c) 2012 Massachusetts Medical Society.

\section{A B STR ACT}

\section{BACKGROUND}

The safety and efficacy of adding antiretroviral drugs to standard zidovudine prophylaxis in infants of mothers with human immunodeficiency virus (HIV) infection who did not receive antenatal antiretroviral therapy (ART) because of late identification are unclear. We evaluated three ART regimens in such infants.

METHODS

Within 48 hours after their birth, we randomly assigned formula-fed infants born to women with a peripartum diagnosis of HIV type 1 (HIV-1) infection to one of three regimens: zidovudine for 6 weeks (zidovudine-alone group), zidovudine for 6 weeks plus three doses of nevirapine during the first 8 days of life (two-drug group), or zidovudine for 6 weeks plus nelfinavir and lamivudine for 2 weeks (three-drug group). The primary outcome was HIV-1 infection at 3 months in infants uninfected at birth. RESULTS

A total of 1684 infants were enrolled in the Americas and South Africa (566 in the zidovudine-alone group, 562 in the two-drug group, and 556 in the three-drug group). The overall rate of in utero transmission of HIV-1 on the basis of Kaplan-Meier estimates was 5.7\% (93 infants), with no significant differences among the groups. Intrapartum transmission occurred in 24 infants in the zidovudine-alone group (4.8\%; 95\% confidence interval [CI], 3.2 to 7.1), as compared with 11 infants in the two-drug group $(2.2 \% ; 95 \% \mathrm{CI}, 1.2$ to $3.9 ; \mathrm{P}=0.046)$ and 12 in the three-drug group $(2.4 \% ; 95 \%$ CI, 1.4 to $4.3 ; \mathrm{P}=0.046$ ). The overall transmission rate was $8.5 \%$ (140 infants), with an increased rate in the zidovudine-alone group $(\mathrm{P}=0.03$ for the comparisons with the two- and three-drug groups). On multivariate analysis, zidovudine monotherapy, a higher maternal viral load, and maternal use of illegal substances were significantly associated with transmission. The rate of neutropenia was significantly increased in the three-drug group ( $\mathrm{P}<0.001$ for both comparisons with the other groups).

CONCLUSIONS

In neonates whose mothers did not receive ART during pregnancy, prophylaxis with a two- or three-drug ART regimen is superior to zidovudine alone for the prevention of intrapartum HIV transmission; the two-drug regimen has less toxicity than the threedrug regimen. (Funded by the Eunice Kennedy Shriver National Institute of Child Health and Human Development [NICHD] and others; ClinicalTrials.gov number, NCT00099359.) 
ANDOMIZED, CONTROLLED STUDIES OF postexposure prophylaxis in infants born to late-presenting women with human immunodeficiency virus (HIV) infection who did not receive antiretroviral therapy (ART) in pregnancy have been performed in breast-fed populations ${ }^{1-5}$ but not in non-breast-fed populations of higherincome countries. Observational studies have shown reduced transmission when zidovudine therapy was initiated within 48 hours after birth and continued for 6 weeks in neonates born to untreated mothers with HIV type 1 (HIV-1) infection, ${ }^{6,7}$ although transmission rates in this scenario remain as high as 12 to $26 \% .^{6-8}$ In a randomized South African trial of infants born to untreated HIV-1-infected mothers, the rates of intrapartum transmission were similar among formula-fed infants receiving zidovudine and those receiving single-dose nevirapine $(11.1 \%$ and $7.3 \%$, respectively; $\mathrm{P}=0.30) .{ }^{5}$ Although use of infant prophylaxis with combination ART is increasing when there is a high risk of HIV-1 transmission, ${ }^{9,10}$ evidence in support of this approach is lacking. We compared the efficacy and safety of three neonatal ART regimens for the prevention of intrapartum HIV-1 transmission in infants whose mothers did not receive ART during pregnancy.

\section{METHODS}

\section{STUDY POPULATION}

HIV-1-infected mothers who had not received ART before labor because of late presentation for medical care were approached for enrollment of their infants. A positive result on a maternal HIV-1 rapid test, pending confirmatory testing, sufficed for enrollment. Women who received antiretroviral drugs other than zidovudine during labor were excluded. All mothers provided written informed consent. Infants were eligible for enrollment if they were no more than 48 hours old, had a gestational age of at least 32 weeks, weighed at least $1.5 \mathrm{~kg}$, had no life-threatening conditions, and were able to take oral medication. Receipt of oral zidovudine before study entry was permitted; infants who received other antiretroviral drugs were excluded.

Enrollment occurred at 17 sites in Brazil, South Africa, Argentina, and the United States. The study was approved by local and collaborating institutional review boards and was reviewed annually by a data and safety monitoring board. Diagnostic kits were purchased for the study, and three of the four study drugs were donated by their respective manufacturers. Study-drug donors did not participate in study design, data accrual, data analysis, or manuscript preparation. All of the authors vouch for the accuracy and completeness of the presented data and the fidelity of this report to the protocol, available with the full text of this article at NEJM.org.

\section{STUDY DESIGN AND TREATMENT REGIMENS}

Infants exposed to HIV-1 were randomly assigned to one of three ART regimens within 48 hours after birth. Fixed dosing based on weight categories was used for drug administration. All infants received zidovudine for 6 weeks, at a dose of $12 \mathrm{mg}$ (for infants with a birth weight $>2.0 \mathrm{~kg}$ ) or $8 \mathrm{mg}$ (for those with a birth weight $\leq 2.0 \mathrm{~kg}$ ) twice daily. The first group received zidovudine alone. The second group received the zidovudine regimen plus three doses of nevirapine: the first within 48 hours after birth, the second 48 hours after the first dose, and the third 96 hours after the second dose. ${ }^{11}$ The nevirapine dose was $12 \mathrm{mg}$ (birth weight $>2.0 \mathrm{~kg}$ ) or $8 \mathrm{mg}$ (birth weight $\leq 2.0$ $\mathrm{kg}$ ) once daily. The third group received the zidovudine regimen plus nelfinavir and lamivudine for 2 weeks. The nelfinavir dose was $200 \mathrm{mg}$ (birth weight $>3.0 \mathrm{~kg}$ ), $150 \mathrm{mg}$ (birth weight $>2.0 \mathrm{~kg}$ and $\leq 3.0 \mathrm{~kg}$ ), or $100 \mathrm{mg}$ (birth weight $\leq 2.0 \mathrm{~kg}$ ) twice daily. The lamivudine dose was $6 \mathrm{mg}$ (birth weight $>2.0 \mathrm{~kg}$ ) or $4 \mathrm{mg}$ (birth weight $\leq 2.0 \mathrm{~kg}$ ) twice daily. ${ }^{12}$

Infants were randomly assigned to a treatment group in blocks of 12. Treatment adherence was evaluated with the use of treatment diaries provided to the mothers or guardians of the infants. In the absence of prior results of maternal HIV-1 testing, HIV-1 infection was diagnosed in mothers by means of rapid testing (Determine [Abbott Laboratories] in Brazil, Johannesburg, and Argentina; OraQuick [OraSure Technologies] in Cape Town, South Africa; and any Food and Drug Administration [FDA]-approved rapid test for HIV-1 and HIV type 2 [HIV-2] antibodies at U.S. sites) during labor and delivery or within 48 hours after birth. Infants were enrolled pending confirmatory test results in mothers. If confirmatory testing was negative, infants who had not received study drugs were withdrawn from 
the study; infants who had received study drugs were followed.

\section{MATERNAL EVALUATIONS}

At study entry, general medical and obstetrical histories were obtained, complete blood counts were obtained, and plasma HIV-1 RNA levels, T-cell subsets, and Venereal Disease Research Laboratory (VDRL) titers were measured. Mothers were counseled not to breast-feed, and infant formula was provided free of charge. Information on breast-feeding was documented.

\section{INFANT EVALUATIONS}

Study visits occurred at birth and at 4 to 7 days, 10 to 14 days, 4 to 6 weeks, and 3 and 6 months of age. Medical histories were obtained and physical examinations were performed at each visit. Complete blood counts and hepatic aminotransferase levels were measured at all visits except at 6 months. The level of HIV-1 DNA was measured with the use of the Amplicor 1.5 DNA polymerasechain-reaction (PCR) assay (Roche Molecular Systems) at all visits except at 4 to 7 days. Laboratory abnormalities were graded with the use of the 1993 Division of AIDS Toxicity Tables for Grading Severity of Pediatric Adverse Experiences. ${ }^{13}$ Grade 3 or higher blood-count abnormalities, grade 2 or higher abnormalities in hepatic aminotransferase levels, and grade 2B or higher rashes were considered serious adverse events. Infants with a positive HIV-1 DNA PCR assay underwent repeat testing as soon as possible. Confirmed HIV-1 infection was defined as two positive results on different days. Infants with positive DNA PCR results at birth and confirmatory positive results on repeat testing were classified as having been infected in utero; such infants were excluded from the primary efficacy analysis. Intrapartum infection was defined as a negative test result at birth with a positive result on subsequent testing. Once HIV-1 infection was confirmed, the study ART prophylaxis was discontinued so that infants could begin ART treatment. All laboratory assays were performed by laboratories that were quality-assured after proficiency testing by the International Maternal Pediatric Adolescent AIDS Clinical Trials (IMPAACT) Group.

Evaluation of genotypic antiretroviral resistance in batched specimens from infected infants was performed with the use of the ViroSeq HIV-1 Ge- notyping System. Specimens were chosen from a time before initiation of ART treatment (with $82 \%$ of specimens from the 3-month visit).

\section{STATISTICAL ANALYSIS}

The target sample size was 1731 infants (577 per study group), with the assumption of a $6 \%$ rate of in utero transmission and a 5\% loss to follow-up. Sample-size calculations were based on intrapartum transmission rates of $9.5 \%$ in the zidovudinealone group, ${ }^{6} 6 \%$ in the two-drug group, and $2 \%$ in the three-drug group, with $80 \%$ power at a $5 \%$ significance level for simultaneous pairwise comparisons between treatment groups. Deaths were considered to be censoring events.

The primary study end point was intrapartum HIV-1 transmission at 3 months of age. The efficacy analysis used the Kaplan-Meier method for determination of transmission rates in each treatment group; all infants with HIV-1 test results were included. A two-stage approach with an extension of the Mantel-Haenszel test was used for comparison of the three Kaplan-Meier curves, followed by a second-stage analysis comparing each pair of transmission rates with the use of two-sample Mantel-Haenszel tests. Hochberg's modified Bonferroni method was used to adjust the significance level for comparisons between groups. ${ }^{14}$ Because of lower-than-expected rates of HIV-1 transmission, comparison of all possible pairs was supplemented by a comparison of monotherapy versus multidrug therapy.

Secondary end points included transmission at additional time points, infant deaths, and risk factors for HIV-1 transmission, including maternal HIV RNA level and CD4+ T-cell count at delivery, status with respect to maternal syphilis, demographic characteristics, obstetrical factors, and status with respect to zidovudine receipt during labor. The evaluation of antiretroviral genotypic resistance in infected infants was descriptive.

Chi-square tests and logistic regression were used to identify risk factors associated with HIV-1 transmission. Only infants with conclusive evidence of HIV-1 status were included in these analyses. In addition, all potential risk factors were tested for interactions with the study treatments. Covariates with a P value of less than 0.20 were entered into a multivariable logistic model. Backward elimination was then used to remove nonsignificant variables, resulting in the final model. 


\section{RESULTS}

\section{BASELINE CHARACTERISTICS OF INFANTS} AND MOTHERS

From April 2004 through July 2010, a total of 1745 infants underwent randomization: 1224 (70.1\%) from Brazil, 479 (27.4\%) from South Africa, $28(1.6 \%)$ from Argentina, and $14(0.8 \%)$ from the United States. Ten infants $(0.6 \%)$ did not receive study drugs. Of the remaining 1735 infants, 51 (2.9\%) had mothers who were HIV-1-negative on confirmatory tests; these infants, whose distribution did not differ significantly among study groups (Table 1), were excluded from efficacy analyses but included in safety analyses. The primary efficacy analysis included 1684 infants.

At baseline, the median age of the mothers was 26 years; $76.3 \%$ were black or of mixed race, $8.8 \%$ had used illegal substances during pregnancy, and $9.3 \%$ had syphilis coinfection (Table 1). The median $\log _{10}$ HIV RNA level was 4.2 copies per milliliter, and the CD4+ T-cell count was 459 per cubic millimeter at delivery. Despite not having received a diagnosis of HIV-1 infection, $62.6 \%$ of the mothers had received prenatal care, with $47.5 \%$ having had at least three prenatal visits. HIV-1 infection was diagnosed by means of rapid testing in $73.2 \%$ of women. A total of $41.0 \%$ of mothers received zidovudine during labor, $99.6 \%$ intravenously; zidovudine use during pregnancy was not associated with HIV-1 transmission $(\mathrm{P}=0.73)$. Cesarean delivery before labor or the rupture of membranes was performed for $23.5 \%$ of infants, with 535 (89.3\%) of 599 cesarean deliveries performed in Brazil. There were no significant differences $(\mathrm{P}>0.05)$ in maternal or infant characteristics among the study groups. The median birth weight was $3.0 \mathrm{~kg}$. Breast-feeding rates, which reflected the peripartum timing of the diagnosis of HIV-1 infection in mothers, were $9.4 \%$ at birth, $1.5 \%$ at 4 to 7 days, and less than $1.0 \%$ the age of 2 weeks or older, with similar rates in the three study groups.

\section{HIV-I INFECTION IN INFANTS}

Overall, 140 (8.3\%) of 1684 infants had HIV-1 infection. The HIV-1 status was unknown for 97 infants (5.8\%): 31 in the zidovudine-alone group, 33 in the two-drug group, and 33 in the three-drug group. All 97 infants had blood specimens collected at birth and tested by PCR assay for the pres- ence of HIV-1 DNA: 95 tested negative; 2 (1 each in the zidovudine-alone and two-drug groups) had a positive DNA test at birth but with no subsequent samples available for testing; 56 had no further specimens collected; 14 had samples between 10 days and 2 weeks (all negative), with no subsequent samples; and 27 had samples between 4 and 6 weeks (all negative), with no subsequent samples.

HIV-1 infection rates by study group, based on Kaplan-Meier curves, are shown in Figure 1 and Table 2. The Kaplan-Meier curves for intrapartum transmission differed significantly among the groups ( $\mathrm{P}=0.03$ for the overall comparison). The overall rate of in utero transmission of HIV-1 was $5.7 \%$, ranging from $5.1 \%$ to $6.8 \%$ across study groups; the rate in the zidovudine-alone group did not differ significantly from the rate in the twodrug group or the rate in the three-drug group ( $\mathrm{P}=0.24$ for both comparisons). The overall rate of intrapartum transmission at 3 months was 3.2\%; the rate in the zidovudine-alone group (24 infants [4.8\%]) was significantly higher than the rates in the two-drug group (11 infants [2.2\%]) and the three-drug group (12 infants [2.4\%]) $(\mathrm{P}=0.046$ for both comparisons). The overall rate of HIV-1 transmission was higher in the zidovudine-alone group (61 infants [11.0\%]) than in the two-drug group (39 infants [7.1\%]) or the three-drug group (40 infants [7.4\%]) ( $\mathrm{P}=0.03$ for both comparisons). These $\mathrm{P}$ values were adjusted for the comparison of the zidovudine-alone group with the two multidrug groups. Adjusted P values for all possible comparisons were 0.07 for the zidovudine-alone group versus the two-drug group, 0.09 for the zidovudine-alone group versus the three-drug group, and 0.80 for the two-drug group versus the three-drug group.

\section{MORTALITY AND LOSS TO FOLLOW-UP}

Forty-three infants (2.6\%) died, with similar mortality in the three groups (11 deaths [1.9\%] in the zidovudine-alone group, 15 [2.7\%] in the two-drug group, and 17 [3.1\%] in the three-drug group) ( $\mathrm{P}=0.49$ by the chi-square test). No deaths were considered to be related to the study drugs. There were 17 deaths in Brazil (1.4\% of 1224 infants) versus 26 in South Africa $(5.4 \%$ of 479 infants, $\mathrm{P}<0.001)$. Sixteen deaths $(37 \%)$ occurred in HIV1-infected infants, $6(14 \%)$ in HIV-1-uninfected infants, and 21 (49\%) in infants with undetermined 
HIV-1 status (see Appendix 2 in the Supplementary Appendix, available at NEJM.org). Reasons for study discontinuation (97 infants) included death (21), withdrawal of consent (37), loss to follow-up (32), relocation (6), and other reasons (1). Participants attended $96 \%$ of the scheduled visits through 3 months; treatment adherence, as assessed on the basis of treatment diaries completed by the mothers or guardians, exceeded $96 \%$ for all study drugs.

RISK FACTORS FOR PERINATAL TRANSMISSION

Factors independently associated with an increased risk of HIV-1 transmission included zidovudine monotherapy, a higher maternal HIV RNA level at delivery, and use of illegal substances during pregnancy (Table 3).

\section{ADVERSE EVENTS}

Neutropenia was the only grade 2 or higher laboratory abnormality that differed significantly among the groups, occurring in $27.5 \%$ of infants in the three-drug group versus $14.9 \%$ in the twodrug group and $16.4 \%$ in the zidovudine-alone group ( $\mathrm{P}<0.001$ for both comparisons by the chisquare test) (Appendix 3 in the Supplementary Appendix). Elevated aminotransferase levels were uncommon (occurring in $2.5 \%$ of all the infants) and did not differ significantly among the groups.

\begin{tabular}{|c|c|c|c|c|c|}
\hline Characteristic & $\begin{array}{c}\text { Overall } \\
(N=1684) \dagger\end{array}$ & $\begin{array}{l}\text { Zidovudine } \\
(\mathrm{N}=566)\end{array}$ & $\begin{array}{l}\text { Zidovudine plus } \\
\text { Nevirapine } \\
(N=562)\end{array}$ & $\begin{array}{l}\text { Zidovudine plus } \\
\text { Nelfinavir and } \\
\text { Lamivudine } \\
(\mathrm{N}=556)\end{array}$ & P Value \\
\hline \multicolumn{6}{|l|}{ Infant's age at time of ART delivery - hrd } \\
\hline Median & & 29 & 28 & 29 & \\
\hline Range & & $2-48$ & $3-48$ & $3-48$ & \\
\hline $\begin{array}{l}\text { Inadvertent enrollment: mother HIV-negative on } \\
\text { confirmatory testing - no./total no. (\%) }\end{array}$ & $51 / 1735(2.9)$ & $15 / 581(2.6)$ & $18 / 580(3.1)$ & $18 / 574(3.1)$ & 0.83 \\
\hline \multicolumn{6}{|l|}{ Maternal age } \\
\hline Median - yr & 26 & 26 & 26 & 26 & 0.86 \\
\hline Range $-\mathrm{yr}$ & $13-47$ & $13-43$ & $14-47$ & $14-45$ & \\
\hline 13-24 yr - no./total no. (\%) & $658 / 1664(39.5)$ & $218 / 563(38.7)$ & $207 / 1230(37.2)$ & $233 / 544(42.8)$ & 0.15 \\
\hline $25-29 \mathrm{yr}-$ no./total no. (\%) & $470 / 1664(28.2)$ & $166 / 563(29.5)$ & $171 / 557(30.7)$ & $133 / 544(24.4)$ & \\
\hline$\geq 30 \mathrm{yr}-$ no./total no. (\%) & $536 / 1664(32.2)$ & $179 / 563(31.8)$ & $179 / 557(32.1)$ & $178 / 544(32.7)$ & \\
\hline \multicolumn{6}{|l|}{ Race - no./total no. (\%) } \\
\hline Black & $819 / 1664(49.2)$ & $273 / 563(48.5)$ & $283 / 557(50.8)$ & $263 / 544(48.3)$ & 0.50 \\
\hline Mixed & $451 / 1664(27.1)$ & $145 / 563(25.8)$ & $147 / 557(26.4)$ & $159 / 544(29.2)$ & \\
\hline White or other & $394 / 1664$ (23.7) & $145 / 563(25.8)$ & $127 / 557(22.8)$ & $122 / 544(22.4)$ & \\
\hline \multicolumn{6}{|l|}{ Viral load — no./total no. (\%) } \\
\hline$>100,000$ copies $/ \mathrm{ml}$ & $226 / 1656(13.6)$ & $71 / 559$ (12.7) & $82 / 554(14.8)$ & $73 / 543(13.4)$ & 0.49 \\
\hline $10,000-100,000$ copies $/ \mathrm{ml}$ & $726 / 1656(43.8)$ & $254 / 559(45.4)$ & $247 / 554(44.6)$ & $225 / 543(41.4)$ & \\
\hline$<10,000$ copies $/ \mathrm{ml}$ & $704 / 1656(42.5)$ & $234 / 559$ (41.9) & $225 / 554(40.6)$ & $245 / 543(45.1)$ & \\
\hline \multicolumn{6}{|l|}{$\log _{10}$ viral load - copies $/ \mathrm{ml} \|$} \\
\hline Median & 4.17 & 4.17 & 4.20 & 4.13 & 0.29 \\
\hline Range & $1.65-6.78$ & $1.65-6.78$ & $1.84-6.36$ & $1.86-6.49$ & \\
\hline \multicolumn{6}{|l|}{ CD4+ count } \\
\hline Median - cells $/ \mathrm{mm}^{3}$ & 459 & 471 & 447 & 458 & 0.83 \\
\hline Range - cells $/ \mathrm{mm}^{3}$ & $12-2678$ & $31-1748$ & $12-2678$ & $23-2556$ & \\
\hline$<200$ cells $/ \mathrm{mm}^{3}-$ no./total no. (\%) & $191 / 1633(11.7)$ & $67 / 548(12.2)$ & $55 / 546(10.1)$ & $69 / 539(12.8)$ & 0.33 \\
\hline $200-350$ cells $/ \mathrm{mm}^{3}-$ no./total no. (\%) & $358 / 1633(21.9)$ & $115 / 548(21.0)$ & $137 / 546(25.1)$ & $106 / 539(19.7)$ & \\
\hline $351-500$ cells $/ \mathrm{mm}^{3}-$ no./total no. (\%) & $358 / 1633(21.9)$ & $115 / 548(21.0)$ & $120 / 546(22.0)$ & $123 / 539(22.8)$ & \\
\hline$>500$ cells $/ \mathrm{mm}^{3}-$ no./total no. (\%) & $726 / 1633(44.5)$ & $251 / 548(45.8)$ & $234 / 546(42.9)$ & $241 / 539(44.7)$ & \\
\hline
\end{tabular}




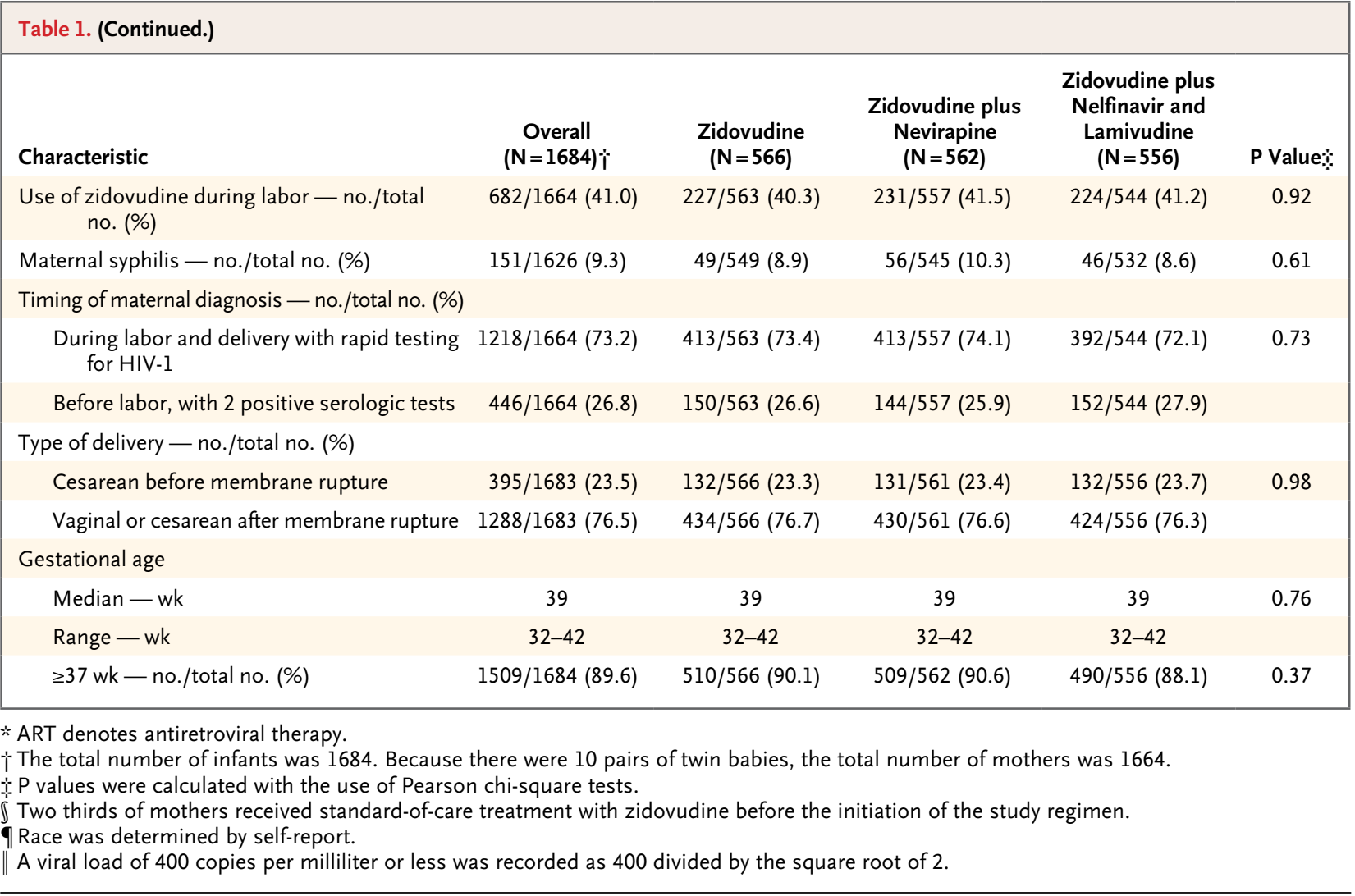

Serious adverse events were observed in $40.1 \%$ of infants: $38.7 \%$ of infants in the zidovudine-only group, $37.0 \%$ of those in the two-drug group, and $44.6 \%$ of those in the three-drug group (Appendix 4 in the Supplementary Appendix). Serious adverse events possibly or probably related to study drugs, as determined by the medical officer of the study sponsor (the Eunice Kennedy Shriver National Institute of Child Health and Human Development [NICHD]), were observed in $8.4 \%$ and $3.4 \%$ of infants, respectively, with higher rates in the three-drug group (12.2\% and $4.9 \%)$ than in the zidovudine-alone group $(6.9 \%$ and $3.7 \%)$ or the two-drug group $(6.2 \%$ and $1.8 \%)$. Neutropenia and anemia accounted for the majority of serious adverse events. Only two skin-related serious adverse events, neither considered by the site investigators and the NICHD medical officer to be related to the study drugs, were reported (one each in the two- and threedrug groups).

\section{ANTIRETROVIRAL DRUG RESISTANCE}

The results of genotypic antiretroviral resistance testing were available for 120 (85.7\%) of 140 HIV- infected infants (Table 4). Mutations conferring resistance to nucleoside analogue reverse-transcriptase inhibitors (NRTIs) were present in 3 infants ( 2 in the three-drug group and 1 in the two-drug group), and mutations conferring resistance to protease inhibitors were present in 2 infants (both in the three-drug group). Mutations conferring resistance to nonnucleoside reverse-transcriptase inhibitors (NNRTIs) were present in 12 infants: 3 (5.7\%) in the zidovudine-alone group, $6(18.2 \%)$ in the two-drug group, and $3(8.8 \%)$ in the three-drug group ( $\mathrm{P}=0.15$ for multiple comparisons). Most NNRTI mutations were detected in infants infected in utero; only 3 infants with intrapartum infection had NNRTI mutations, 1 in each group. There were no significant differences in the distribution of resistance mutations among the groups.

\section{DISCUSSION}

This study compared ART prophylactic regimens in a solely formula-fed population of infants whose mothers had not received antenatal ART. On the basis of the results of the Pediatric AIDS Clinical Trials Group Protocol 076 study, ${ }^{15}$ the standard 


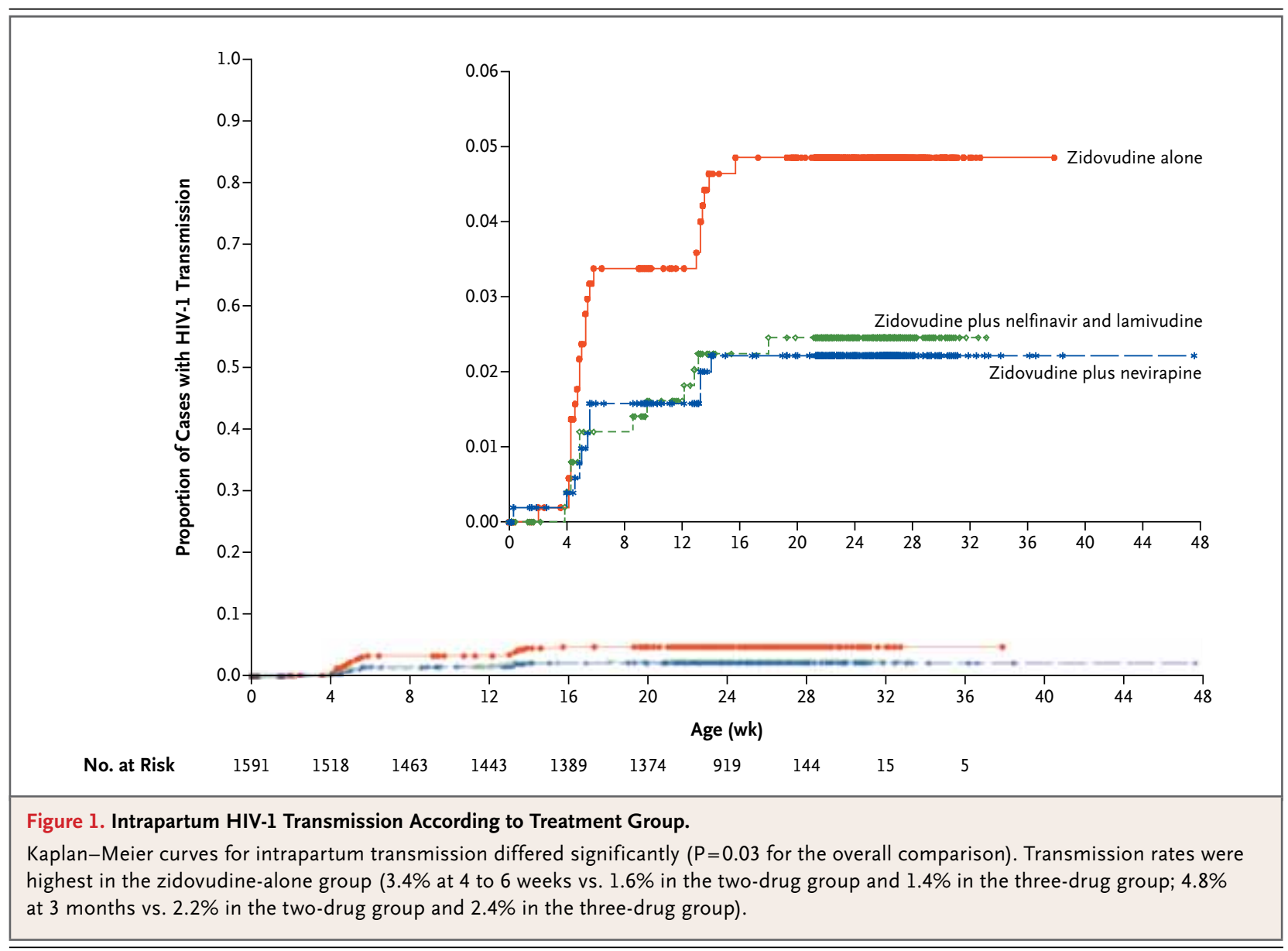

ART prophylactic regimen for infants born to HIV1-infected mothers in high-income and middleincome countries has been a 6-week course of zidovudine. ${ }^{16,17}$ In our study, the overall transmission rate in the zidovudine-alone group (11\%) was similar to rates in observational studies in which zidovudine was initiated within 48 hours after birth in postpartum-identified HIV-1-exposed infants. ${ }^{6,7,18}$ Intrapartum transmissions were reduced by half in the two- and three-drug groups in our study, as compared with the zidovudinealone group. When we designed the study, we hypothesized that a protease-inhibitor-based threedrug ART regimen might confer a higher level of protection against intrapartum HIV transmission than would a two-drug regimen, given the high virologic efficacy of protease-inhibitor-based treatment regimens. ${ }^{19,20}$ However, intrapartum infection rates were similar in the multidrug groups in our study.

Although intrapartum infection rates were about half as high as anticipated, with consequent loss of power, we observed significant differences in infection rates. Although transmission rates were similar in the multidrug groups, ease of administration favors the zidovudine-nevirapine regimen (a liquid formulation of nevirapine is commercially available, whereas nelfinavir powder requires reconstitution before each dose). Moreover, unlike nevirapine, ${ }^{11}$ the absorption of nelfinavir in neonates is quite variable. ${ }^{12}$ At present, other protease inhibitors are not recommended in the neonatal period, given the adverse effects of lopinavir-ritonavir ${ }^{21}$ and FDA restrictions on its use in infants younger than 14 days of age. Neutropenia was significantly more common with the threedrug regimen than with the other two regimens, a difference that is probably related to the combined suppressive effects of zidovudine and lamivudine on bone marrow production of blood cells. ${ }^{22-24}$

Although NNRTI resistance was observed more frequently in the two-drug group, NNRTI resistance mutations were present in all three groups, most frequently among infants infected in utero. 


\begin{tabular}{|c|c|c|c|c|c|}
\hline Infection Status & $\begin{array}{c}\text { Overall } \\
(\mathrm{N}=1684)\end{array}$ & $\begin{array}{l}\text { Zidovudine } \\
(\mathrm{N}=566)\end{array}$ & $\begin{array}{l}\text { Zidovudine plus } \\
\text { Nevirapine } \\
(N=562)\end{array}$ & $\begin{array}{l}\text { Zidovudine plus } \\
\text { Nelfinavir and } \\
\text { Lamivudine } \\
(\mathrm{N}=556)\end{array}$ & P Value \\
\hline \multicolumn{6}{|l|}{ Infected in utero } \\
\hline Infants - no. & 93 & 37 & 28 & 28 & \\
\hline Kaplan-Meier rate — \% $(95 \% \mathrm{Cl})$ & $5.7(4.7-6.9)$ & $6.8(5.0-9.3)$ & $5.1(3.5-7.3)$ & $5.2(3.6-7.4)$ & 0.24 \\
\hline \multicolumn{6}{|l|}{ Infected during intrapartum period } \\
\hline \multicolumn{6}{|l|}{$4-6 \mathrm{wk}$} \\
\hline Infants - no. & 32 & 17 & 8 & 7 & \\
\hline Kaplan-Meier rate — \% (95\% Cl) & $2.1(1.5-3.0)$ & $3.4(2.1-5.4)$ & $1.6(0.8-3.1)$ & $1.4(0.7-2.9)$ & 0.07 \\
\hline \multicolumn{6}{|l|}{$3 \mathrm{mo}$} \\
\hline Infants - no. & 47 & 24 & 11 & 12 & \\
\hline Kaplan-Meier rate — \% (95\% CI) & $3.2(2.4-4.2)$ & $4.8(3.2-7.1)$ & $2.2(1.2-3.9)$ & $2.4(1.4-4.3)$ & 0.046 \\
\hline \multicolumn{6}{|l|}{ Infected in utero or during intrapartum period } \\
\hline Infants - no. & 140 & 61 & 39 & 40 & \\
\hline Kaplan-Meier rate — \% $(95 \% \mathrm{CI})$ & $8.5(7.3-10.0)$ & $11.0(8.7-14.0)$ & $7.1(5.2-9.6)$ & $7.4(5.4-9.9)$ & 0.03 \\
\hline Uninfected - no. & 1447 & 474 & 490 & 483 & \\
\hline Unknown - no. & 97 & 31 & 33 & 33 & \\
\hline \multicolumn{6}{|c|}{$\begin{array}{l}\text { Transmission rates and } 95 \% \text { confidence intervals were estimated on the basis of Kaplan-Meier curves for in utero, intrapartum, and overall } \\
\text { transmission. Patients who died or were lost to follow-up were included in this analysis. Infants who were inadvertently enrolled were ex- } \\
\text { cluded from the analysis. } \\
\text { The } \mathrm{P} \text { values for the pairwise comparisons were calculated with the use of Hochberg's modified Bonferroni approach, with adjustment for } \\
\text { two pairwise comparisons. The two pairwise comparisons were zidovudine versus zidovudine plus nevirapine and zidovudine versus zid- } \\
\text { ovudine plus nelfinavir and lamivudine; because of the Hochberg adjustment, the } \mathrm{P} \text { values were identical for the two comparisons. }\end{array}$} \\
\hline
\end{tabular}

Baseline rates of primary NNRTI resistance of 4 to $11 \%$ have been reported among Brazilian patients, and transmission of resistant virus from mother to child could explain the presence of NNRTI resistance in all the groups in our study. ${ }^{25-27} \mathrm{Ma}-$ ternal resistance testing to gain a better understanding of the genesis of infant antiretroviral resistance is under way. Coadministration of zidovudine decreases NNRTI resistance after exposure to single-dose nevirapine. ${ }^{28}$ The clinical significance of NNRTI resistance in infants may be limited, because protease-inhibitor-based therapy is highly effective in infants and is recommended in World Health Organization and U.S. guidelines for the treatment of pediatric HIV infection in infants exposed to NNRTI-based regimens for the prevention of mother-to-child transmission of HIV. ${ }^{29,30}$

Factors independently associated with an increased rate of HIV-1 transmission included zidovudine monotherapy, a higher maternal HIV RNA level at delivery, and maternal use of illegal substances. The latter two have been associated with high rates of HIV transmission in multiple studies. ${ }^{31-35}$ Although our study identified improved prophylactic alternatives for infants born to late-presenting HIV-1-infected mothers, the present approach does not substitute for the prevention and early identification of HIV-1 infection in women, with prompt initiation of ART during pregnancy. Prenatal care was received by $63 \%$ of the mothers in our study, with $48 \%$ having had at least 3 visits; these findings indicate that there were numerous missed opportunities to diagnose maternal HIV-1 infection and provide prophylaxis against mother-to-child transmission. Provision of ART prophylaxis in infants will not prevent in utero infection, which accounted for $70 \%$ or more of the residual infection in the two- and three-drug groups.

Like the findings in studies investigating rapid intrapartum and postpartum HIV-1 testing, ${ }^{36,37}$ our findings show that large-scale rapid HIV-1 testing during labor or the immediate postpartum period, followed by prompt initiation of ART in infants, is feasible, acceptable, and effective. The 


\begin{tabular}{|c|c|c|c|c|c|c|}
\hline \multirow[t]{3}{*}{ Characteristic } & \multirow[t]{2}{*}{ Infected } & \multirow[t]{2}{*}{ Uninfected } & \multicolumn{4}{|c|}{ Odds Ratio $(95 \% \mathrm{Cl})$} \\
\hline & & & Unadjusted & P Value & Adjusted* & P Value \\
\hline & \multicolumn{2}{|c|}{ no./total no. (\%) } & & & & \\
\hline \multicolumn{7}{|l|}{ Treatment group } \\
\hline Zidovudine plus nelfinavir and lamivudine & $12 / 528(2.3)$ & $516 / 528(97.7)$ & $0.49(0.24-0.99)$ & 0.047 & $0.50(0.24-1.01)$ & 0.05 \\
\hline Zidovudine plus nevirapine & $11 / 534(2.1)$ & $523 / 534(97.9)$ & $0.44(0.21-0.91)$ & 0.03 & $0.39(0.19-0.82)$ & 0.01 \\
\hline Zidovudine & $24 / 529(4.5)$ & $505 / 529(95.5)$ & 1.00 & & 1.00 & \\
\hline \multicolumn{7}{|l|}{ Age } \\
\hline $13-24 \mathrm{yr}$ & $20 / 627(3.2)$ & $607 / 627(96.8)$ & $0.85(0.45-1.60)$ & 0.61 & & \\
\hline $25-29 \mathrm{yr}$ & $8 / 437(1.8)$ & $429 / 437(98.2)$ & $0.48(0.21-1.11)$ & 0.08 & & \\
\hline$\geq 30 \mathrm{yr}$ & $19 / 507(3.7)$ & $488 / 507(96.3)$ & 1.00 & & & \\
\hline \multicolumn{7}{|l|}{ Race } \\
\hline Black & $29 / 776(3.7)$ & $747 / 776(96.3)$ & $1.56(0.73-3.32)$ & 0.25 & & \\
\hline Mixed & $9 / 425(2.1)$ & $416 / 425$ (97.9) & $0.87(0.34-2.21)$ & 0.77 & & \\
\hline White or other & $9 / 370(2.4)$ & $361 / 370(97.6)$ & 1.00 & & & \\
\hline Illegal-substance use during pregnancy & $7 / 137(5.1)$ & $130 / 137(94.9)$ & $1.87(0.82-4.25)$ & 0.14 & $2.51(1.08-5.86)$ & 0.03 \\
\hline Increased $\log _{10}$ viral load & & & $2.16(1.49-3.13)$ & $<0.001$ & $2.28(1.56-3.35)$ & $<0.001$ \\
\hline Increased CD4+ count & & & $0.90(0.81-1.01)$ & 0.08 & & \\
\hline \multicolumn{7}{|l|}{ Prenatal care } \\
\hline No & $18 / 592(3.0)$ & $574 / 592(97.0)$ & $1.02(0.56-1.86)$ & 0.94 & & \\
\hline Yes & $29 / 974(3.0)$ & $945 / 974(97.0)$ & 1.00 & & & \\
\hline \multicolumn{7}{|l|}{ Use of zidovudine during labor } \\
\hline No & $29 / 931(3.1)$ & 902/931 (96.9) & $1.11(0.61-2.02)$ & 0.73 & & \\
\hline Yes & $18 / 640(2.8)$ & $622 / 640(97.2)$ & 1.00 & & & \\
\hline \multicolumn{7}{|l|}{ Syphilis } \\
\hline Yes & $3 / 134(2.2)$ & $131 / 134(97.8)$ & $0.71(0.22-2.31)$ & 0.57 & & \\
\hline No & $44 / 1403(3.1)$ & $1359 / 1403(96.9)$ & 1.00 & & & \\
\hline \multicolumn{7}{|l|}{ Region } \\
\hline Americas & $30 / 1124(2.7)$ & $1094 / 1124(97.3)$ & $0.69(0.38-1.27)$ & 0.24 & & \\
\hline South Africa & $17 / 447(3.8)$ & $430 / 447(96.2)$ & 1.00 & & & \\
\hline \multicolumn{7}{|l|}{ Type of delivery } \\
\hline Cesarean before membrane rupture & $7 / 373(1.9)$ & $366 / 373(98.1)$ & $0.56(0.25-1.27)$ & 0.17 & & \\
\hline $\begin{array}{l}\text { Vaginal or cesarean after membrane } \\
\text { rupture or timing unknown }\end{array}$ & $40 / 1217(3.3)$ & $1177 / 1217(96.7)$ & 1.00 & & & \\
\hline \multicolumn{7}{|l|}{ Gestational age } \\
\hline $32-36$ wk & $6 / 165(3.6)$ & $159 / 165(96.4)$ & $1.28(0.53-3.05)$ & 0.59 & & \\
\hline$\geq 37$ wk & $41 / 1426(2.9)$ & $1385 / 1426(97.1)$ & 1.00 & & & \\
\hline
\end{tabular}

* All available demographic and clinical variables were tested for their association with transmission. P values are for the significance of the association with transmission from mother to infant. All variables with a $P$ value of 0.20 or less were included in the multivariable regression model. Variables with a $\mathrm{P}$ value of more than 0.20 were then removed from the model. The backward-elimination method was used to select the final model. This model used maternal viral load and maternal CD4+ count as continuous variables in addition to treatment group and illegal substance use. The odds ratios shown for $\log _{10}$ viral load and CD4+ count are associated with a 1-log increase in the viral load or a 100-cell increase in the CD4+ count. The CD4+ count was eliminated from the final adjusted model. 


\begin{tabular}{|c|c|c|c|c|c|}
\hline \multirow[t]{2}{*}{ Mutation } & Overall & Zidovudine & $\begin{array}{l}\text { Zidovudine plus } \\
\text { Nevirapine }\end{array}$ & $\begin{array}{l}\text { Zidovudine plus } \\
\text { Nelfinavir and } \\
\text { Lamivudine }\end{array}$ & P Value ${ }^{\prime}$ \\
\hline & \multicolumn{4}{|c|}{ no. of infants/total no. (\%) } & \\
\hline \multicolumn{6}{|c|}{ NRTI-associated mutations } \\
\hline In utero & $2 / 79(2.5)$ & $0 / 32$ & $0 / 23$ & $2 / 24(8.3)$ & 0.17 \\
\hline Intrapartum & $1 / 41(2.4)$ & $0 / 21$ & $1 / 10(10.0)$ & $0 / 10$ & 0.49 \\
\hline Overall & $3 / 120(2.5)$ & $0 / 53$ & $1 / 33(3.0)$ & $2 / 34(5.9)$ & 0.17 \\
\hline \multicolumn{6}{|c|}{ PI-associated mutations } \\
\hline In utero & $2 / 79(2.5)$ & $0 / 32$ & $0 / 23$ & $2 / 24(8.3)$ & 0.17 \\
\hline Intrapartum & $0 / 41$ & $0 / 21$ & $0 / 10$ & $0 / 10$ & - \\
\hline Overall & $2 / 120(1.7)$ & $0 / 53$ & $0 / 33$ & $2 / 34(5.9)$ & 0.15 \\
\hline \multicolumn{6}{|c|}{ NNRTI-associated mutations } \\
\hline In utero & $9 / 79(11.4)$ & $2 / 32(6.2)$ & $5 / 23(21.7)$ & $2 / 24(8.3)$ & 0.19 \\
\hline Intrapartum & $3 / 41(7.3)$ & $1 / 21(4.8)$ & $1 / 10(10.0)$ & $1 / 10(10.0)$ & 1.00 \\
\hline Overall & $12 / 120(10.0)$ & $3 / 53(5.7)$ & $6 / 33(18.2)$ & $3 / 34(8.8)$ & 0.15 \\
\hline \multicolumn{6}{|c|}{$\begin{array}{l}\text { Any mutations associated with PIs, } \\
\text { NNRTIs, or NRTIs }\end{array}$} \\
\hline In utero & $10 / 79(12.7)$ & $2 / 32(6.2)$ & $5 / 23(21.7)$ & $3 / 24(12.5)$ & 0.20 \\
\hline Intrapartum & $4 / 41(9.8)$ & $1 / 21(4.8)$ & $2 / 10(20.0)$ & $1 / 10(10.0)$ & 0.53 \\
\hline Overall & $14 / 120$ (11.7) & $3 / 53(5.7)$ & $7 / 33(21.2)$ & $4 / 34(11.8)$ & 0.09 \\
\hline
\end{tabular}

* Although 140 infants had HIV-1 infection, 20 did not have results from the ViroSeq assay owing to missing specimens or failure of the assay (i.e., the viral load was too low for amplification). The following mutations were considered clinically significant for resistance: D67G, L210W, T215S, K219E, D67 N, T215Y, K65R, K70R, and K219R for nucleoside analogue reverse-transcriptase inhibitors (NRTIs); L10I, D30 N, A71V, and N88D for protease inhibitors (PIs); and Y181C, K103 N, V179E, E138K, V106A, V106 M, V181I, A98G, and V179D for nonnucleoside reverse-transcriptase inhibitors (NNRTIs). Some infants had more than one mutation.

$\uparrow \mathrm{P}$ values, which were calculated with the use of Fisher's exact test, are for multiple comparisons.

high level of acceptability of postexposure ART prophylaxis in infants is reflected by $96 \%$ adherence. In settings where zidovudine prophylaxis is the standard of care for HIV-exposed infants whose mothers have not received ART during pregnancy, our study shows that the administration of additional antiretroviral drugs significantly reduces the risk of intrapartum acquisition of HIV, as compared with zidovudine alone. Our findings are pertinent to countries in which combination ART in mothers throughout pregnancy is standard and ongoing exposure to HIV-1 through breast-feeding does not occur. Our results support combination ART regimens instead of zidovudine alone for prophylaxis in the infants of mothers who have not received antenatal ART. Ease of use, reduced toxicity, availability, and low cost suggest that zidovudine plus nevirapine is an attractive option for prophylaxis in infants at high risk for perinatal HIV-1 infection.

The views expressed in this article are those of the authors and do not necessarily reflect the views of the National Institutes of Health or the Department of Health and Human Services.

Presented in part at the 18th Conference on Retroviruses and Opportunistic Infections, Boston, February 27-March 2, 2011.

Supported by the NICHD (HHSN267200800001C, N01HD-8-0001) and by a grant from the HIV Prevention Trials Network, which is funded by the National Institute of Allergy and Infectious Diseases (NIAID), to the Brazilian AIDS Prevention Trials International Network at the University of California, Los Angeles (U01 AI047986). Overall support for IMPAACT, which endorsed the study, was provided by grants from the NIAID (U01 AI068632), the NICHD, and the National Institute of Mental Health (AI068632).

Disclosure forms provided by the authors are available with the full text of this article at NEJM.org.

We thank the patients and their families who enrolled in this trial; and Marita McDonough and Lauren Petrella from Boehringer Ingelheim Pharmaceuticals and Helen Watson from GlaxoSmithKline (on behalf of ViiV Healthcare) for assistance with the donation of study drugs from their respective companies for the conduct of the study. 


\section{APPENDIX}

The authors' affiliations are as follows: David Geffen School of Medicine, University of California, Los Angeles, Los Angeles (K.N.-S., Y.J.B.); the Eunice Kennedy Shriver National Institute of Child Health and Human Development, National Institutes of Health, Bethesda (D.H.W., G.S., J.M., L.M.M.), and Westat, Rockville (J.B., M. Camarca, J.X.) - both in Maryland; the Laboratório de Pesquisa Clínica em DST e AIDS, Instituto de Pesquisa Clínica Evandro Chagas (V.G.V., B.G.), the Laboratório de AIDS e Imunologia Molecular, Instituto Oswaldo Cruz (J.H.P., M.G.M.), and the Laboratório de Informações em Saúde, Instituto de Informação Científica e Tecnológica em Saúde (R.I.M., F.I.B.), Fundação Oswaldo Cruz (Fiocruz), the Hospital Federal dos Servidores do Estado (E.C.J.), and the Hospital Geral de Nova Iguaçu (J.H.P.) - all in Rio de Janeiro; the Perinatal HIV Research Unit, University of Witwatersrand and Chris Hani Baragwanath Hospital, Johannesburg (G.G.), and Stellenbosch University and Tygerberg Hospital, Cape Town (G.T.) - both in South Africa; Hospital Conceicao (B.S.), Hospital Femina (R.F.), and Irmandade da Santa Casa de Misericordia de Porto Alegre (R.K.), Porto Alegre, RS; Federal University of Minas Gerais, Belo Horizonte, MG (J.P.); Universidade de Sao Paulo, Ribeirao Preto, SP (M.M.M.-P.); and Universidade Federal de Sao Paulo, Sao Paulo, SP (D.M.) - all in Brazil; the Foundation for Maternal and Infant Health, Buenos Aires (M. Ceriotto); University of California, Davis, Davis (R.D.); and Boston University School of Medicine, Boston (M.M.).

REFERENCES

1. Guay LA, Musoke P, Fleming T, et al. Intrapartum and neonatal single-dose nevirapine compared with zidovudine for prevention of mother-to-child transmission of HIV-1 in Kampala, Uganda: HIVNET 012 randomised trial. Lancet 1999;354:795802.

2. Taha TE, Kumwenda NI, Gibbons A, et al. Short postexposure prophylaxis in newborn babies to reduce mother-tochild transmission of HIV-1: NVAZ randomised clinical trial. Lancet 2003;362: 1171-7.

3. Taha TE, Kumwenda NI, Hoover DR, et al. Nevirapine and zidovudine at birth to reduce perinatal transmission of HIV in an African setting: a randomized controlled trial. JAMA 2004;292:202-9.

4. Chasela CS, Hudgens MG, Jamieson DJ, et al. Maternal or infant antiretroviral drugs to reduce HIV-1 transmission. N Engl J Med 2010;362:2271-81.

5. Gray GE, Urban M, Chersich MF, et al. A randomized trial of two postexposure prophylaxis regimens to reduce mother-tochild HIV-1 transmission in infants of untreated mothers. AIDS 2005;19:1289-97.

6. Wade NA, Birkhead GS, Warren BL, et al. Abbreviated regimens of zidovudine prophylaxis and perinatal transmission of the human immunodeficiency virus. N Engl J Med 1998;339:1409-14.

7. Veloso VG, Bastos FI, Portela M, et al. HIV rapid testing as a key strategy for prevention of mother-to-child transmission in Brazil. Rev Saude Publica 2010;44:803-11. 8. Fiscus SA, Adimora AA, Schoenbach VJ, et al. Trends in human immunodeficiency virus (HIV) counseling, testing, and antiretroviral treatment of HIVinfected women and perinatal transmission in North Carolina. J Infect Dis 1999;180:99-105.

9. McKeegan K, Rutstein R, Lowenthal E. Postnatal infant HIV prophylaxis: a survey of U.S. practice. AIDS Patient Care STDS 2011;25:1-4.

10. Haile-Selassie H, Townsend C, Tookey $\mathrm{P}$. Use of neonatal post-exposure prophylaxis for prevention of mother-to-child HIV transmission in the UK and Ireland, 2001-2008. HIV Med 2011;12:422-7.

11. Mirochnick M, Nielsen-Saines K, Pi- lotto $\mathrm{JH}$, et al. Nevirapine concentrations in newborns receiving an extended prophylactic regimen. J Acquir Immune Defic Syndr 2008;47:334-7.

12. Mirochnick M, Nielsen-Saines $\mathrm{K}, \mathrm{Pi}-$ lotto $\mathrm{JH}$, et al. Nelfinavir and lamivudine pharmacokinetics during the first two weeks of life. Pediatr Infect Dis J 2011; 30:769-72.

13. Division of AIDS (DAIDS) Regulatory Support Center. Table for grading severity of pediatric adverse experiences: less than 3 months of age. April 1994 (http://rsc .tech-res.com/safetyandpharmacovigilance/ gradingtables.aspx).

14. Hochberg Y. A sharper Bonferroni pro cedure for multiple tests of significance. Biometrika 1988;75:800-2.

15. Connor EM, Sperling RS, Gelbert R, et al. Reduction of maternal-infant transmission of human immunodeficiency virus type 1 with zidovudine treatment. $\mathrm{N}$ Engl J Med 1994;331:1173-80.

16. Panel on Treatment of HIV-Infected Pregnant Women and Prevention of Perinatal Transmission. Recommendations for use of antiretroviral drugs in pregnant HIV-1-infected women for maternal health and interventions to reduce perinatal HIV transmission in the United States. September 14, 2011 (http://aidsinfo.nih.gov/ ContentFiles/PerinatalGL.pdf).

17. Recommendations for the prevention of vertical transmission of HIV and antiretroviral treatment for pregnant women 2010. Brazil Ministry of Health, 2010 (http://www.aids.gov.br/publicacao/ consenso-recomendacoes-para-profilaxiada-transmissao-vertical-do-hiv-e-terapiaantirretr). (In Spanish.)

18. Nogueira SA, Abreu T, Oliveira R, et al. Successful prevention of HIV transmission from mother to infant in Brazil using a multidisciplinary team approach. Braz J Infect Dis 2001;5:78-86.

19. Krogstad P, Wiznia A, Luzuriaga K, et al. Treatment of human immunodeficiency virus 1 -infected infants and children with the protease inhibitor nelfinavir mesylate. Clin Infect Dis 1999;28. 1109-18.

20. Krogstad P, Lee S, Johnson G, et al. Nucleoside-analogue reverse-transcriptase inhibitors plus nevirapine, nelfinavir, or ritonavir for pretreated children infected with human immunodeficiency virus type 1. Clin Infect Dis 2002;34:991-1001. 21. Simon A, Warszawski J, Kariyawasam D, et al. Association of prenatal and postnatal exposure to lopinavir-ritonavir and adrenal dysfunction among uninfected infants of HIV-infected mothers. JAMA 2011;306:70-8.

22. Mandelbrot L, Landreau-Mascaro A, Rekacewicz C, et al. Lamivudine-zidovudine combination for prevention of maternal-infant transmission of HIV-1. JAMA 2001;285:2083-93.

23. El Beitune P, Duarte G. Antiretroviral agents during pregnancy: consequences on hematologic parameters in HIV-exposed, uninfected newborn infant. Eur J Obstet Gynecol Reprod Biol 2006;128:59-63.

24. Lambert JS, Nogueira SA, Abreu T, et al. A pilot study to evaluate the safety and feasibility of the administration of AZT/ 3TC fixed dose combination to HIV infected pregnant women and their infants in Rio de Janeiro, Brazil. Sex Transm Infect 2003;79:448-52.

25. Pedroso C, Queiroz AT, Alcântara LC, et al. High prevalence of primary antiretroviral resistance among HIV-1-infected adults and children in Bahia, a northeast state of Brazil. J Acquir Immune Defic Syndr 2007;45:251-3.

26. Sprinz E, Netto EM, Patelli M, et al. Primary antiretroviral drug resistance among HIV type 1-infected individuals in Brazil. AIDS Res Hum Retroviruses 2009; 25:861-7.

27. Inocencio LA, Pereira AA, Sucupira MC, et al. Brazilian Network for HIV Drug Resistance Surveillance: a survey of individuals recently diagnosed with HIV. J Int AIDS Soc 2009;12:20.

28. Eshleman SH, Hoover DR, Hudelson $\mathrm{SE}$, et al. Development of nevirapine resistance in infants is reduced by use of infant-only single-dose nevirapine plus zidovudine postexposure prophylaxis for the prevention of mother-to-child transmission of HIV-1. J Infect Dis 2006;193:479-81. 29. Antiretroviral therapy for HIV infection in infants and children: towards universal access: recommendations for a 
public health approach: 2010 revision. Geneva: World Health Organization, 2010 (http://whqlibdoc.who.int/publications/ 2010/9789241599801_eng.pdf).

30. Panel on Antiretroviral Therapy and Medical Management of HIV-Infected Children. Guidelines for the use of antiretroviral agents in pediatric HIV infection. August 11, 2010 (http://aidsinfo.nih .gov/ContentFiles/PediatricGuidelines.pdf). 31. Sperling RS, Shapiro DE, Coombs RW, et al. Maternal viral load, zidovudine treatment and the risk of transmission of human immunodeficiency virus type 1 from mother to infant. N Engl J Med 1996;335: 1621-9.
32. Dickover RE, Garraty EM, Herman SA, et al. Identification of levels of maternal HIV-1 RNA associated with risk of perinatal transmission: effect of maternal zidovudine treatment on viral load. JAMA 1996; 275:599-605.

33. Marazzi MC, Liotta G, Nielsen-Saines $\mathrm{K}$, et al. Extended antenatal antiretroviral use correlates with improved infant outcomes throughout the first year of life. AIDS 2010;24:2819-26.

34. Purohit V, Rapaka RS, Shurtleff D. Mother-to-child transmission (MTCT) of HIV and drugs of abuse in post-highly active antiretroviral therapy (HAART) era. J Neuroimmune Pharmacol 2010;5:507-15.
35. Ellis RJ, Childers ME, Cherner M, et al. Increased human immunodeficiency virus loads in active methamphetamine users are explained by reduced effectiveness of antiretroviral therapy. J Infect Dis 2003; 188:1820-6.

36. Bulterys M, Jamieson DJ, O'Sullivan MJ, et al. Rapid HIV-1 testing during labor: a multicenter study. JAMA 2004;292: 219-23.

37. Theron GB, Shapiro DE, Van Dyke R, et al. Rapid intrapartum or postpartum HIV testing at a midwife obstetric unit and a district hospital in South Africa. Int J Gynaecol Obstet 2011;113:44-9.

Copyright @ 2012 Massachusetts Medical Society. 